Discourse and Communication for Sustainable Education, vol. 7, no. 1, pp. 100-111, 2016

\title{
Sustainability by Education: How Latvian Heritage was Kept Alive in German Exile
}

\author{
Geert Franzenburg \\ University of Muenster, Germany
}

\begin{abstract}
Sustainability is one of the core challenges for education in modern times, particularly concerning cultural heritage. The study evaluates, from a German point of view, how Latvians outside of Latvia after World War II kept their cultural heritage alive by educational concepts, which can be characterized as early roots of modern sustainable education. The evaluation focus concerns a group of Latvians in Germany associated with the Latvian high school in Muenster (MLG). The study concerns the 25 years from 1957 (school relocation to Muenster) until 1982 (founding of the organization "Latvian Center of Muenster e.V." (LCM), and combines interviews and literature research. It underlines that environmental, social and heritage education can be seen as core elements of Latvian education abroad. Therefore, the study will not present a concise history of the Latvian high school in Muenster (MLG), which has already been done (Sprogis, 2009), but will concisely evaluate the educational concepts of this particular period as a model, how Latvians maintained their heritage in a sustainable way.
\end{abstract}

Keywords: education, exile, heritage, Latvian, school, sustainability

The United Nations Decade of Education for Sustainable Development (DESD, 2005-2014) has demonstrated that educational sustainability means integration of the ecological, economic, cultural, and political components into the curriculum by integrating values of sustainable development into all aspects of education and learning (UNESCO, 2012). Although these are challenges and purposes of the 21st century, traces can be found as early as 1960, when UNESCO was founded. A few years before 1960, the Latvian School changed its location from Augustdorf to Muenster. In April 1957 with 84 students, this school became famous as MLG (Minsteres Latviešu gimnazija), and maintained Latvian heritage during exile times. Particularly important was the formation of literature, theater and folklore groups.

The school was founded 1946 in Detmold and settled in the DP camp in Augustdorf after World War II. It was one of at least 56 secondary schools and 111 primary schools for Latvian refugees. Some students from Detmold went to a Greven secondary school (Spogis, 2009). When the School moved to Muenster it was housed in former German 
army barracks but soon a new school was built by the city of Muenster, the school and the dormitory moved to Wienburg street. The dormitory for the school children was administered by the Lutheran Perthes Werk, the name of the accommodation was "Haus Riga”. Latvian students from Germany and all over the world attended the school - as the wealth level of the former refugees increased - their children from the USA, Canada, England, Sweden, and Australia were able to live in the dormitory and attend the school. Renown Latvian literati gave readings at the school because it was also a regional Latvian culture center. Artists, such as Janis Jaunsudrabiņš and Zenta Mauriņa, were honored with small museums that were situated in the school as part of the school library. Thus, for the Latvian community outside of Latvia MLG became the pinnacle of Latvian exile education as the only full time Latvian school. After 1965, students and teachers came to the MLG school from all over the world, and built a concentrated Latvian community as the main mission of the school. On the other hand, MLG succeeded to integrate the advantages of both school systems, the Latvian and the German. (Franzenburg, 2010; Spogis 2009).

When the German administration decided to withdraw funding and, thus, aims to close the school (starting with the dormitory) in 1980, families and friends of the worldwide MLG community supported the school with donations and delayed the closure.

In 1982, the Latvian Center Muenster (LCM) was founded as a registered German organization This organization decided to build a new house for the dormitory. Later on, the impressive amount of donations the LCM had accrued caused the German government to reward this funding initiative with a big government grant and the organization - the Latvian Center Muenster - built not only the dormitory, as initially planned, but also a new school building. An interesting name change emphasized that the project was not just a local project, or the "Muenster Latvian Center" as had been the name of the school - the "Muenster Latvian Gymnasium", MLG, but it was now the Latvian Center that just incidentally happened to be in Muenster. Thus, two Latvian organizations became responsible: The Latvian Central Community adopted the responsibility for the school administration, and the Latvian Center Muenster adopted the responsibility for the building (and later the dormitory) until the final closing of the MLG school in 1998. The building of the MLG school, the Latvian Center, continues to uphold the Latvian heritage outside of Latvia thus being sustainable. In addition to the educational purpose of MLG high school, there was always a large social, economic and ecological/environmental aspect or added value, which, therefore, underlines the symbiotic character of such integrated education (Ohlemeier, 2013, 6).

The following study evaluates how these principles of sustainable education and learning can be found in the educational concepts and practices of Latvian pupils in exile and diaspora. Therefore, the following questions will be answered:

How does the particular economic framework of exile influence teaching and learning?

What are the contents, which contribute to such environment and context?

What are appropriate methods to facilitate social, cultural and ecological learning? What is the particular contribution of Latvian heritage to sustainable education? 


\section{How Cultural Heritage Can be Kept Alive in Exile}

In order to find out, how the particular framework of exile influences teaching and learning, a short survey about the context of the MLG should explain, why Latvians lived as "Displaced Persons" or refugees in Germany after World War II, and how they were coping with this particular situation in an educational way.

In a second step, the learning and teaching contents are evaluated concerning their contribution to the particular challenges of an exile context.

The third step concerns the methodical issue: How can such exile oriented contents be taught and learned in such an appropriate way, which facilitates social, environmental and cultural education?

Summarizing, for the particular Latvian aspect: How can the way, in which Latvian cultural heritage is kept alive, become a model for sustainable education in other contexts?

These observations and considerations are the main issues for discussion about the opportunities to maintain cultural identity within a foreign framework, and for educational conclusions in analogue situations. Based on the detailed and concise history of the MLG by A. Spogis (2009), core documents concerning the context of Latvian education between 1957 and 1982 are evaluated, which explain and illustrate, how Latvians in Germany were coping with the challenges of exile, and how they developed educational concepts, materials, methods and environments that facilitate keeping Latvian heritage alive.

The published literature, interviews, memoirs, and other documents are evaluated by an elementary form of "grounded theory": the documents were analyzed concerning core categories (main and subcategories) and terms, which can be compared with the principles of social, cultural and environmental teaching and learning as core aspects of sustainable education:

The following items can be found and explained:

\section{Exile and Education}

In 1944, together with hundreds of thousands of refugees, who had to escape the Soviet aggression and occupation of their homelands, thousands of Latvians settled in the Western Zones of Germany, where they lived in "Displaced Persons (DP) or refugee camps under the care of UN organizations (UNRRA and IRO) (Franzenburg, 2012, 2013, and 2014; Jacobmeyer, 1985; Schroeder, 2005; Wyman, 1989). In 1950, German administration took over the responsibility for those, who were not resettled in other countries (for e.g. England or overseas: USA, Canada, Australia).

A core element, particular of Latvian culture within the camps, was education in camp schools. Because of the massive refugee emigration, when Germany was in ruins after the ravages of the war, more and more of these camp schools were closed. There were fluctuations not only in the number of pupils, but one also had to find substitutes for the many emigrated teachers.

The schools were concentrated and one of the last camp schools was settled in Detmold and later in Augustdorf as an institution of the main Latvian organization (founded in 1946) the Latvian Community of Germany (LKV) with its administrative board, the Latvian Central Committee. (LCK). In 1957, as already mentioned, this school structure moved to Muenster and became known as the Latvian Gymnasium in Muenster (MLG). 
It was chaired by a "conference", which was approved by LCK and by German authorities. The German authorities payed the salary of some teachers - others often got less salary from the Latvian institutions. The school programs had to adjust from the improvised camp variants based on the former Latvian school system, to the necessary and binding regulations of the local German government. Most of the time the pupils lived in the school, and to enhance the programs of school life in exile the LCK set its cultural standards. Therefore, teachers and students, had to balance between autonomous cultural identity and assimilation by applying a particular kind of integration of their "Latvianess" into the German society, and into German environment (Spogis, 2009).

Concerning the purposes of a sustainability oriented education, they had to - so to say - integrate or juggle economical needs as mandated by particular financial supporters with an orientation to German standards with the Latvian yearnings for a free and independent Latvia as a core task and challenge during the stay in Germany. In the first years during and after WW II the hope that it may be possible to return to Latvia dominated. Therefore, LCK suggested that the educators prepare the community for common national and Christian standards. They encouraged discipline, school maintenance and extracurricular events as part of a pupil's upbringing. These events included facilitating recitations, theaters, excursions, performances and other events, as mentioned in the newspaper "Latvija", No 5, 1960, on February 6. In his history of the MLG, A. Spogis evaluated the conferences and meetings of the Latvian Central Committee (LCK) with other institutions, such as the conferences, which consisted of members of the LCK, the administrations of Muenster and Northrhine-Westphalia to supervise the work of the MLG. Thus, Spogis demonstrates that in addition to maintaining Latvianess as a core challenge in exile, the additional challenges for the MLG, were to find sufficient students that conformed to German rules and standards, the need to find additional financial support, when the minimum was not reached, or to build new buildings when the extent ones were minimized or taken away. (Spogis, 2009). This underlines the economic chances and limitations of maintaining cultural identity and heritage, and demonstrates, how educational and monetary aspects interact concerning the purpose of educational sustainability.

\section{Exile Oriented Contents}

\section{Language}

One core element, which allows a particular autonomy within a foreign environment, is the mother tongue, not only for Latvians, but in any minority or Diaspora community.

German and Latvian language were both obligatory subjects at MLG (six hours a week German from the third class (if needed, also earlier)). Most of the textbooks were in German, but teaching was in Latvian language, particular religious teachings, Latvian history and geography. As a key, which opened the way into one's own cultural identity and heritage, the Latvian language was exercised not only like other languages (German, Latin, English, French, later Russian), but encoded in literature, folklore, music, songs, dancing, encounters etc. Since most of the pupils lived in the dormitory, the everyday language at mealtimes, play, activities, etc. was Latvian. Even at conferences - like in May 1958 by the LCK Committee on Culture, the invited professionals, educators and students, used the Latvian language to discuss cultural questions, and, at the same time, shared a cultural event. Two years later, at a LCP conference, the issue was discussed that many Latvian families preferred teaching the Latvian language at home rather 
than at school, while the schools should prepare children in German for studies at German universities, as mentioned in the newspaper "Latvija" No 5, 1960, on February 6.

Therefore, concerning sustainability in education, the value of mother tongue for cultural identity and maintaining cultural heritage cannot be overestimated; as a core element in folk-poems and songs, it contributes a lot to maintain a sense of belonging, not only for Latvians, but also on Poland and other countries (Rode, 2013; Switala, 2013). Thus, educators, while integrating refugees into a school community, should appreciate, facilitate and encourage opportunities to share the different languages, their characteristics and meanings in a learning group.

\section{Remembrance Days}

In order to make MLG both, a place to prepare to become a member of the German society, and a place to experience Latvianess, the annual National or Independence Day (November 18), was celebrated. To the outside, the young people gathered in the morning and raised the Latvian flag in front of the school building along the German, North-Rhine-Westphalia and European flags as a core event and "lieu de mémoire" (Nora, 2005).

In 1963, during one such event, the headmaster, Prof. Dr. Z. Vitens, emphasized the fight with long arms against the oppression of the Latvian people, by keeping the homeland in one's heart at all times, and remembering the life and work of the ancestors. (Spogis, 2009, 49).

Therefore, concerning sustainability in education - similar to mother tongue - the value of such "lieux de mémoire" (Nora, 2005) for cultural identity and maintaining cultural heritage cannot be overestimated, too. Thus, educators, while integrating refugees into a school community, should appreciate, facilitate and encourage opportunities to share the different religious and cultural traditions by common celebrations during the year.

\section{Literature}

Evaluating the content of the school library of MLG illustrates the purpose of European integration of Latvianess. The books combine Latvian exile literature, and literature from Soviet and independent Latvia with European literature (German, English, French, Italian, Spanish, Scandinavian), poetic works and practical advice for agriculture or gardening, material for choirs, dance groups and folklore groups, philosophical and religious literature and learning books (grammar, vocabulary, mathematics, natural sciences, most of them rooted out after 1998 and sent to schools in Latvia.

Between 1947 and 1967 there were an increase of about 30\% to about 15000 books, most of them in Latvian (over 4000), German (about 2600), and English 1195) for 84 pupils (Dagis, 1983, 221, and 224/25). The library also contains political agitation concerning Soviet occupation and the Latvian freedom struggle (Franzenburg, 2014).

This core aspect of heritage is also demonstrated in the school archive, and school museums which undoubtedly are more than just "school library" additions. (Maurina, Raudive, Jaunsudrabinš̌).

Therefore, concerning sustainability in education - similar to mother tongue and remembrance days - the value of literary heritage for cultural identity and maintaining cultural heritage is crucial, and can be transferred particularly into modern non literary refugee communities with mostly oral tradition. Thus, educators should appreciate, 
facilitate and encourage opportunities to share and compare literary heritage from different cultures, in order to learn from each other, and facilitate a common (European) cultural identity by maintaining individual and ethnic ones.

\section{Exile Oriented Methods}

\section{Family education}

As already mentioned, and confirmed by the Latvian pupils in Latvia today (Franzenburg, 2015), and by interview partners from 2008 (unpublished), Latvian language and culture is primary taught in the family, where Latvianess is facilitated and maintained. Particularly in mixed families this is a core challenge, which needs the cooperation of all partners, as mentioned in the newspaper "Latvija” No. 6, 1971, on January 13. The pupils of MLG came from different family situations, some lived in the boarding school, others, who lived with their families, were excluded from the community or had a harder time involving themselves in activities. Evaluating the curriculum of the American Latvian Association (ALA) for Latvian schools in America (and abroad), one notes the emphasis on everyday life issues, and on memorizing songs, poetry, and tales and recognizing and knowing Latvian symbols, celebrations, history and geography as core issues for a Latvian cultural identity, as well as for maintaining cultural identity in any Diaspora situation.

\section{Religious Education}

Religiousness, too, is seen as a core aspect of Latvian culture, particularly concerning the care for the lost homeland. In 1974, when the MLG school celebrated the 18th of November Independence day, there was a religious part to the ceremonies. Vicar K. Valdmanis reminded that the homeland could become occupied, but never the spirit of the Latvian people, and invited the participants to pray for the occupied people, but also for all Latvians abroad, because God's freedom would not leave Latvia in the dark, as mentioned in the newspaper "Latvija” 1974, on January 19 (Franzenburg, 2013).

The core value of religiousness, particularly concerning the Lutheran tradition, is demonstrated by the inclusion and emphasis on Christian rituals during graduations and other ceremonies, and by the authoritative or crucial role of theologians, particularly the archbishops (Lūsis and Grīnbergs) for remembrance culture and collective memory (Spogis, 2009). According to different confessions, religions and denominations, for many people living in Diaspora, religious attitudes become core strategies of coping with such situations, particularly for maintaining cultural identity.

\section{Dramatizing}

As a particular characteristic of MLG, literature (drama) often was transferred into theater or at least role play. One further method to let the students make experiences with theater and identity issues, is to develop dramatic work by themselves, for e.g. the play "Youth dream" (1974), where Latvianess is emphasized. It illustrates the dream of the Latvian soul longing for Latvia as a princess bride longs for the prince on his white horse. Such activities teach people to discuss Latvianess. One man states as an answer to the question:" what does Latvianess mean?" the following:

"To be Latvian, it is not enough just to speak Latvian, to sing Latvian folk songs, or to dance in Latvian folk groups to be familiar with Latvian literature 
and art or to put on the Latvian folk costume... It is to be much more than that, to be stronger, to be greater... My parents are Latvians - so I am also Latvian!"

A Latvian teacher explains national holidays once again using the illustration of Latvia as the dreaming princess. He also suggests to continue fighting for Latvian autonomy. Another quotation cites the Latvian poet Vilis Plūdons, saying, "it is not possible to fly a modern airplane, but you can go with Latvian soul light made wings!" mentioned in the newspaper "Latvija," 1974, on January 19. Other examples of methods to become integrated without being assimilated, are Christmas ceremonies, where German and Latvian elements were combined. In 1975, a student had written a play named "A Christmas Pear". Parts of the play involved irrational phases to create a mood of multilateralism, and the desire to move away from reality, as well as to try to find answers to the questions of existence, as mentioned in the newspaper "Latvija," 1976, on January 6.

Such examples confirm the crucial meaning of creative expressing one's cultural identity in any historical context, in order to maintain it.

\section{Music, Arts and Sports}

Folk dance groups, such as "Circenitis," (The Grasshoppers), and later the folk musical Mičotāji (based on Latvian wedding traditions), choirs and other groups performed Latvianess in a traditional and at the same time, creative way, not only in MLG, but on tour in other towns in Germany and Europe, and even as far as the US and Australia.

Besides culture, sport activities, in particular basketball, were crucial elements of cultural identity, because encounters, competitions and events became part of "Little Latvia" (Spogis, 2009). Through sports and success as Latvian basketball players, there were contacts to the German world, and pride as Latvians for the positive achievements.

While pupils of different ages did homework together in one study room, the singing and exercising activities in the afternoons, took place in separate rooms and in classrooms or other areas of the school, and sometimes individually as well (for. e.g music instruction) (Spoğis, 2009).

Similar to dramatizing, such examples, too, underline, how creative and active common expressing one's cultural identity can help maintaining it in any historical context.

\section{Education as a Coping Strategy in Exile}

\section{Participation in the Struggle for Freedom}

During conferences and Remembrance Day celebrations, such as Independence day (November 18) and Deportation Day (June 14), the task and challenge of the school, particularly in the 1960s, was to fight peacefully or to demonstrate for a free homeland.

The commemoration was combined with thanks for support and cooperation of the local politicians, and with a warning and appeal towards the West to recognize the Baltic suffering and to support the freedom struggle in a political way; so that informed countries prevent themselves from getting into a similar fate as the Soviet occupied countries, as mentioned in the newspaper "Latvija," 1966. 


\section{Facilitating Educational Weapons for This Struggle}

The head of the administrative "school conference," J. Dagis, emphasized in an article that for 20 years MLG had facilitated Latvian education and provided room for the students from Germany to expand the cradles of the independence to share this with the Latvian refugees abroad in America, Canada, and Australia. Therefore, they should learn the Latvian language, know the Latvian fate, and have a deep understanding of the freedom spirit. This was a particular challenge for mixed partnerships and families in Germany and elsewhere. Thus, they might become motivated to engage in Latvian organizations, such as the European Latvian Youth Association (ELJA), and to perform Latvian arts, literature, music and dance or folklore as professionals in order to prevent assimilation, as mentioned in the newspaper "Latvija," 1966 on November 5 (Spogis, 2009).

\section{Finding One's Place in Society}

First of all, the Latvian language is seen as the magic link from exile to the homeland and from the past towards the future. Nevertheless, MLG had to cope with competitive German and English schools, but even so emphasized the value of the Latvian language and culture, similar to other post-soviet nations, such as Poland (Switala, 2013), as core aspects of education.

Poets, such as Rainis, who knew from personal experience about exile, and, thus, suggest love for the homeland, or who emphasized the community, were chosen as stable elements of the curriculum, and therefore, a core content of literature in school and class.

The core challenge, however, was motivating Latvian parents to allow their children to attend a Latvian school, as they had promised themselves 23 years ago, when they first became refugees, as mentioned in the newspaper "Latvija" No 20, 1967, on April 27. Therefore, the MLG faculty members had to balance between the needs of the Latvian families and the restrictions of German authorities concerning the number of students and teachers and role of the German language, as mentioned in the newspaper "Latvija" No 23, 1967, on June 17.

\section{Preparing the Youth - Preparing the Future}

During its entire existence MLG taught more than 2.200 Latvian children, and many became confident Latvians; 155 students graduated (acquired the German Abitur) (71 boys and 84 girls); after graduating many enrolled in German universities and technical universities. Until the end of the 1970s, the graduates of the Latvian high school had to take special "diligence tests" at the German universities to prove that their qualifications with the Latvian Diploma were as valid as the German ones. Many studied in other countries as well, often receiving advanced credits for the work done in Germany.

Celebrating 25 years of MLG, the anniversary was accompanied by Communist and other attacks, pessimists grumbled, gossips, rumor perpetrators and personal preference critics were loud, but none of these could stop the school's efforts.

As a core contribution of MLG towards exile societies in general, and the Latvian community in particular, the educational model of cooperation and tolerance is mentioned 
and suggested for all Latvians. Because the Latvian youth is the Latvian future and hope, MLG inculcated an awareness for Latvian traditions, history, narrations, geography, culture, and, first and foremost, the Latvian language. Therefore, MLG is seen as the big chance not only to preserve Latvian cultural heritage, and mental traditional content for the future, but also to give opportunities for young people to experience Latvianess, and to transfer it into a free and united Europe as a loudness storm (Nietzsche) or a volcano belched from hidden depths with the Latvian souls as seismographs from a different perspective towards the parent's native land, as mentioned in the newspaper "Latvija" No 5, 1971, on February 6.

The graduation ceremonies are combined with religious ceremonies and rituals (1981 Emmaus-model), which suggest following Christ into eternal life (Lizdiks, Liepkalns). These have left a lasting imprint, and, thus, are often mentioned by graduates even 50 years later.

One additional reason for this emphasis might be to counter the Communist atheist attitude, because particularly during the 1980s the KGB seemed to be very interested in the schools activities, and invited students to visit their occupied homeland during these years, as mentioned in the newspaper "Latvija" No 24, 1981, on June 22. Thus MLG became part of the Baltic activities during Cold War times (Hiden, 2008).

The evaluation underlines the value of language and culture for maintaining cultural identity and heritage. Furthermore, lacking paper, books and other material facilitated a kind of environmental education: one had to rely on the scant materials that were available and recreate a lot of school materials from memory, not only in MLG alone, but also in other schools (Kapeikis, 2007). It also explains how social aspects (events, encounters) support the maintaining of the heritage. That the students lived in a dorm or attended school very near to the school, who first were living in the barracks, before the school was integrated with the dorm, underlines the environmental aspect.

Although these examples characterize particularly the Latvian situation, modern refugees, and other people who which to keep their cultural identity and heritage in abroad alive and sustainable, tend to combine considering about their identity with political attitudes.

\section{Looking Back After 50 Years}

Following the international covenant on economic, social and cultural rights adopted by the UN in 1960, "the inherent dignity and of the equal and inalienable rights of all members of the human family is the foundation of freedom, justice and peace in the world" (UN, 1960), the adequate education model has to recognize that these rights derive from the inherent dignity of the human person, and has to facilitate that free human beings can enjoy freedom from fear and want by creating conditions, whereby everyone may enjoy his/her economic, social and cultural rights, as well as his civil and political rights. Concerning the particular aspect of exile, such education also includes political aspects, such as the relationship between exile and Soviet Latvia or between Latvians and Germans.

The answers of interview partners 50 years later (unpublished), underline the value of such a singular school program, particularly when they remember graduations and other school events. Although the rural and forest environment of Augustdorf was more agreeable, they built up a similar one in Muenster as their "Little Latvia", e.g. by 
decorating the auditorium with nature flowers and birch boughs or oak wreaths for the event celebrations, especially when celebrating the midsummer event.

Others remember the good quality of education, not only the academic one, but also the social one. People were qualified for jobs, and had a good attitude towards work, which underlined the practical aspects (cleaning the room, washing dishes, setting the tables) of the MLG program. The availability of literature in the library (books, newspapers, magazines) was important. The shared responsibility of not only the teachers, but activity leaders, dorm personnel and activity groups including parents prepared the future leaders to be responsible community members as an important part of good education.

Traditions and narrations (mostly oral) are often mentioned. One core aspect of family life was prayer, and the transmission of values and beliefs. Some of the interviewees, however, were orphans or came from complex family situations; their answers show that the school often transmitted values that usually would be associated with those acquired in a family. The range of parents/family interview issues underlines the formative value of the MLG environment for their children, even 50 years later. Further, remembrance is also a core issue for the interview partners, as a mostly ambivalent phenomenon. Therefore, history often was a preferred discipline in school. Contemporary Latvian pupils, who were interviewed in 2015, remember the mentioned events from their families' childhood (Franzenburg, 2015).

Remembrance Days, thus, like other "memory marker", can be important markers to define cultural identity and facilitate patriotism (Hilton, 2009).

Another core issue is community, particular the identification with one's school, class or with groups such as the boy scouts, or dance groups which were an internal Latvian community without external contacts. Sometimes Latvian organizations, such as LCP and LCK, are mentioned. Many answers mention baptism and confirmation as important life events and remember the school pastor or priest, and, thus, underline the value of Christian religion, and particularly the majority Lutheran tradition, for childhood and later life. Latvian culture is often mentioned as a coping resource, particularly emphasizing group singing and theater productions, also group sports and teams (basketball and volleyball). Besides the Latvian language, the MLG emphasized foreign languages and they were a part of the school curriculum from the very beginnings of the MLG school (Latin, French, German, English, later Russian). Of course the natural sciences, mathematics and civic education especially history were also important in the school curriculum.

Because of the lack of schoolbooks during the early MLG years, teaching was done by teacher narrations - perhaps a reason, why teachers became important authorities and models (often female teachers). Later on, the teachers wrote their own texts drawing on the vast information available from German and English materials. A further, perhaps the most often mentioned core issue in the answers is the homeland Latvia and the longing for return or for the opportunity to visit Latvia freely. This is often combined with the Russian or Soviet trauma that families were separated by the Iron curtain, since it was almost impossible to leave Latvia and very difficult, as well as expensive, to acquire a visa to visit Latvia. These memories confirm, what was intended, and documented in Latvian newspapers.

Although the term "sustainable" is not mentioned, maintaining Latvianess and the hope for a free homeland with complicated economical, social, cultural and ecological implications was alive. 
The pupils confirm the core value of heritage education is documented by answers to a questionnaire from 13 th class students, as mentioned in the newspaper "Latvija" No 39, 1980, on October 18. The answers underline that the students want to combine both: integrating into the German society and maintaining their cultural identity as Latvians. Therefore, they have chosen to attend MLG, because of the Latvian language and Latvian encounters. Some particularly emphasized the political struggle for Latvia's independence, but the common emphasis was on the value of the "shared Latvianess" experienced in the MLG school situation. Although these pupils were not born in their parents' or grandparents' native land, the wish to encounter international contacts, be in Europe and perhaps even visit Latvia were important reasons to attend the MLG school. All MLG students hoped to grow spiritually as well as physically by integration into the cultural diversity of Europe, the experience of a different socialization than the one brought along (often economically very different) but most of all, the intense Latvian immersion provided by the school. Thus, their answers support the suggestions and resolutions of LCK and LCP that Latvian parents worldwide and particularly those in Germany, should send their children to MLG, as mentioned in the newspaper "Latvija" 1981, on November 6.

\section{Conclusion}

When in 1982 the Latvian Center in Muenster was founded as a non-governmental organization, the goal was to promote education for Latvians in Germany, firstly through the building of a new dormitory and later a new school building. The organization was never intended to be "just a house", but defined its supplementary goals to be rather broad, namely to support Latvian culture and tradition, support children, students and retired people, facilitate international and tolerant intercultural understanding, include research in Latvian culture and history.

Therefore, the building was from the very start a cultural center, and, in addition to the classrooms and dormitory, it was built, as already mentioned, with space for the school library, archives, multifunctional event auditoriums, museums, a gallery, and seminar rooms, a kindergarten and even rooms for producing the Latvian exile newspaper. Thus, that the end of the MLG school in 1998 has not resulted in an end of all Latvian activity in the Latvian Center of Muenster, is a significant example of sustainability in education.

This center continued, what UNESCO some decades later might also have had in mind, when defining education for sustainable development (ESD) as a complex notion combining knowledge, competencies, skills, values and behaviors (Iliško et al., 2014; Sterling, 2002). Its history from the early MLG times, can, therefore, be characterized as a contribution for civic education (Ohlemeier, 2013). MLG tried successfully, at least concerning heritage education, to equip students with greater humility, with respect for all forms of life and future generations, endowed a capacity to think systematically, to challenge unethical decisions and to increase all part of knowledge and the necessary skills to create a sustainable future.

Although the UN program of sustainability in education is a modern one, its traces can be found in the way the MLG tried to maintain Latvian heritage even while living in exile. These goals were achieved by encouraging pupils to share ideas and ideals with others in order to enrich the present and shape their individual and national future in the European value family. 


\section{References}

Baltic Refugees and Displaced Persons (1947). London: Boreas Publishing.

Dagis, J. (1983). Die lettischen Bildungsanstalten in Deutschland [Latvian institutions of education in Germany]. Acta Baltica 23, 203-258.

Franzenburg, G. (2013-15), TRIMDA Forum 2-4, Germany: Münster.

Franzenburg, G. (2016). Erinnern verbindet [Remembrance encounters]. Norderstedt. Bod.

Franzenburg, G. (2012). Distance, remembrance, tolerance: European remarks. PEC 47, 40-49.

Franzenburg, G. (2013). Displaced values: From remembrance to resilience. PEC, 56, 59-65.

Franzenburg, G. (2010). MLG-LCM 1945-2010. Germany: Münster.

Hilton, L. (2009). Cultural nationalism in exile: the case of polish and Latvian displaced persons. Historian 71(2), 2080-317.

Hiden, J., Made, V., Smith, D. (Ed.) (2008). The Baltic question during the cold war. UK: Oxford.

Iliško, D., Skrinda, A., \& Mičule, I. (2014). Envisioning the future: Bachelor's and Master's degree students' perspectives. Journal of Teacher Education for Sustainability, 16(2), 88-102.

Jacobmeyer, W. (1985). Vom Zwangsarbeiter zum Heimatlosen Auslaender, Die Displace Persons in Westdeutschland 1945-1951. [From forced worker to homeless stranger. Displaced persons in western Germany 1945-1951]. Germany: Göttingen.

Kapeikis, H. S. (2007). My exile from Latvia. CA: Victoria.

Nora, P. (2005). Erinnerungsorte Frankreichs [Memory places in France]. Germany: München.

Ohlmeier, B. (2013). Civic education for sustainable development. Discourse and Communication for Sustainable Education 4, 5-22.

Rode, O. (2013). Educational and psychological aspects of environmental awareness and a sense of belonging. Discourse and Communication for Sustainable Education, 4, 67-79.

Schröder, S. (2005). Displaced persons im Landkreis und in der Stadt Münster 19451951 [Displaced Persons in the region and town of Muenster 1945-1951]. Germany: Muenster.

Spog̣is, A. (2009). Minsteres Latviešu Gimāzija 1946-1998. [The Latvian High school in Muenster, 1946-1998] Latvia: Riga.

Sterling, S. (2002). Sustainable education: Re-visioning learning and change. UK: Bristol.

Switala, E. (2013). Values education: a reality or myth in polish schools. Discourse and Communication for Sustainable Education, 4, 57-66.

UNESCO (2012). Education for sustainable education sourcebook, Paris. Retrieved May 1, 2015, from http://unesdoc.unesco.org/images/0021/002163/216383e.pdf Wyman, M. (1989). Dps. Europe's displaced persons, 1945-1951, US: Philadelphia.

Correspondence concerning this paper should be addressed to Geert Franzenburg. Email: franzenburg@t-online.de 